is helping to produce a feeling of solidarity among inorganic chemists which never existed hitherto. Even in Germany, the stronghold of organic chemistry, the address of van't Hoff is exciting wide interest, and the Chemiker Zeitung, in urging the establishment of independent chairs and lab. oratories of inorganic chemistry, is advocating what will in time unquestionably be realized.

Inorganic chemistry is fortunate in that its renaissance is coming about at a time when physical methods are in vogue. The prediction of Du Bois-Reymond is being realized ; with the aid of physics it is attaining an insight into the dynamical aspect of the science which it could never have reached unassisted. But it is not alone by supplying new methods and suggesting new points of view that physics is aiding the revival of inorganic chemistry. Perhaps equally important is the fact that the rising school of physical chemists, unhampered by the traditions and limitations of organic chemistry, is finding it necessary to explore the whole range of the science in search of material for its investigations. The physical chemist is neither organic nor inorganic, or rather he is either, according to his requirements, but it is precisely because the inorganic field is wider and less developed than the organic that his demands are more likely to be productive of activity.

Energetics is now the basis of chemistry, and it is to be expected, therefore, that inorganic chemistry will not, in the future, have to pass through a period of arrested development and formula worship, such as have so long affected organic chemistry. There will always be compound makers, but their aim will be, not the establishment of constitutional formulas alone, but the study of the laws of chemical energy and the solution of the problem of the nature of matter. We may expect, too, that the still sharp line of demarcation between inorganic and organic chemistry and between dead and living matter will disappear. The inorganic chemist may not affect the synthesis of a proteid, but he will be able, with his wider knowledge, to contribute more to the solution of the problem of the nature of life than any amount of structurizing and synthesizing alone can do. To comprehend life we must understand carbon, but we can no more fully comprehend carbon without an understanding of the other elements than we can explain the earth without a knowledge of the other planets, or man without a knowledge of the fish. He, then, who pursues inorganic chemistry is not only contributing to a higher development of our science than can be reached by the study of carbon compounds alone, but is perhaps doing as much as the organic chemist toward realizing one of the greatest aims of research, the comprehension of life and its explanation in terms of physical science.

$$
\text { Washington, D. C. H. N. Stokes. }
$$

\section{ON THE TOTAL SOLAR ECLIPSE OF} MAY 28, 1900.

THE next total solar eclipse will be visible as such in places both east and west of the Atlantic Ocean, and it is a matter of some thought to determine where it shall be observed. I have proposed to report to the governing board of Williams College that it is practicable to observe it on both sides at points to be fully determined later, as at present there is rather more than a year's time to make the needful arrangements.,

The two countries where it shall be observed seem to be Portugal and our own Southern States, in the neighborhood of Coimbra and that of Norfolk, in Virginia, or perhaps farther south. The only doubt is the more or less uncertainty of weather. That, however, cannot be avoided, as the meteorologists are not yet able to predict with much certainty or at all for more 
than a few days at a time. The Weather Bureaus at Washington and Lisbon will, of course, do all that they can, but the most that can now be done is to observe the weather in 1899 , in the hope of getting some new light on the matter.

So far as the eclipse is concerned, which will certainly take place at the predicted time, it is possible and practicable to make calculations from the data in our American Ephemeris, and to do this within a few days, and in the coming months to make all needful preparations of instruments and training of observers, and with abundant spare time left.

I shall report to our trustees that the main effort to be made then will be towards photographing the eclipse as well and completely at both points as the time, short enough at best, will allow.

At Norfolk, in Virginia, and Ovár, in Portugal, the eclipse will be total long enough to be well photographed by instruments costing but little more than a hundred dollars for each station, instruments which can be made useful in several directions and can be readily placed at either station. The advantage of making the effirt to observe at both places will be, of course, not that of making observations at the same time, but that of following out a uniform set of rules both in America and in Europe.

These rules can be readily formulated and practiced beforehand with comparatively little trouble, provided the astronomers can come to an agreement, which I think will be an easy matter.

The process of taking the photographs is so easy now that no difficulty will arise from this, and it will also be easy to train intelligent students into the necessary physical manipulations, with the help, at least, of the necessary photographers, who, I presume, will be readily brought to either station.
As the object of the present paper is merely to indicate what is to be done, I shall defer to another occasion any further details. In this, as in many other problems of practical astronomy, the main requirement is merely to indicate in common language the problems to be solved, and it will be sufficient to leave further consideration of the matter to another occasion.

\section{Truman Henry Safford.}

\section{RECEPTION AND EXHIBITION OF THE NEW YORK ACADEMY OF SCIENCES.}

The Annual Reception and Exhibition of the New York Academy of Sciences has come to be one of the most interesting social events of the scientific circles of the city. This fine spring weather and a beautifully suitable hall combined with the zeal of the exhibitors to furnish instructive entertainment to about three thousand persons. The reception was held, as usual, at the American Museum of Natural History, the first evening being reserved for members, exhibitors and special friends, and some 500 availed themselves of this opportunity to become better acquainted with their fellow members, and to see and discuss the advances in branches of science other than their own. Indeed, the justification and benefits of these exhibitions are to be sought quite as much in their broadening influence upon the point of view of specialists as in their possibilities for the layman and amateur.

The Museum authorities are exemplary in their hospitality, and the relations between this gigantic object lesson in science and the Academy are yearly growing more cordial. This year it was possible to hold the reception in the new hall of American Anthropology, west of the entrance on the main floor. The room is finished, but is not yet occupied by cases and permanent fixtures. A more suitable and appropriate location for a scientific reception it would be hard to imagine. 